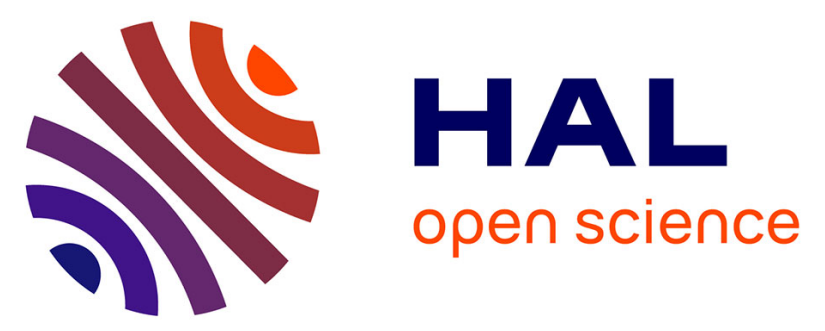

\title{
Latex Imaging by Environmental STEM: Application to the Study of the Surfactant Outcome in Hybrid Alkyd/Acrylate Systems
}

Jenny Faucheu, Laurent Chazeau, Catherine Gauthier, Jean-Yves Cavaille, Monika Goikoetxea, Roque Minari, José Maria Asua

\section{To cite this version:}

Jenny Faucheu, Laurent Chazeau, Catherine Gauthier, Jean-Yves Cavaille, Monika Goikoetxea, et al. Latex Imaging by Environmental STEM: Application to the Study of the Surfactant Outcome in Hybrid Alkyd/Acrylate Systems. Langmuir, 2009, 25 (17), pp.10251-10258. 10.1021/la901049h . hal-00539996

\section{HAL Id: hal-00539996 https://hal.science/hal-00539996}

Submitted on 25 Nov 2010

HAL is a multi-disciplinary open access archive for the deposit and dissemination of scientific research documents, whether they are published or not. The documents may come from teaching and research institutions in France or abroad, or from public or private research centers.
L'archive ouverte pluridisciplinaire HAL, est destinée au dépôt et à la diffusion de documents scientifiques de niveau recherche, publiés ou non, émanant des établissements d'enseignement et de recherche français ou étrangers, des laboratoires publics ou privés. 


\title{
Latex imaging by Environmental STEM: Application to the study of the surfactant outcome in hybrid alkyd/acrylate systems
}

\author{
Jenny Faucheu", Laurent Chazeau", Catherine Gauthier ${ }^{\#}$, Jean-Yves Cavaillé" ${ }^{\#}$, Monika \\ Goikoetxea $^{\circ}$, Roque Minari ${ }^{\circ}$ José M. Asua $^{\circ}$
}

"MATEIS, INSA-Lyon, 7 avenue Jean Capelle, 69621 Villeurbanne, France

${ }^{\circ}$ Institute for Polymer Materials, POLYMAT, Departamento de Química Aplicada, University of the Basque Country, Centro Joxe Mari Korta, Avenida Tolosa 72, 20018 Donostia-San Sebastián, Spain.

\begin{abstract}
Among other uses, latexes are a successful alternative to solvent-borne binders for coatings. Efforts are made to produce hybrid nanostructured latexes containing an acrylic phase and an alkyd phase. However, after film forming process, the surfactant used to stabilize these latexes remains in the film and its location can have drastic effect on the application properties. Among the processing parameters, the alkyd hydrophobicity can strongly influence this location. This article aims at the imaging of these surfactant molecules in two hybrid latex with different hydrophobicity level of the alkyd resin. A first part of this paper is dedicated to the understanding of the contrast provided by the surfactant in environmental STEM imaging of latexes. Then the influence of surfactant-polymer affinity on the surfactant location after film forming of those hybrid alkyd/acrylate latexes is studied by this technique. It is shown that in the hybrid latex with an alkyd shell (obtained with the most hydrophilic resin), the surfactant molecules tend to remain buried in the alkyd phase. Conversely, in the
\end{abstract}


hybrid latex with an acrylate shell (in the case of the most hydrophobic resin), the surfactant molecules tend to gather into islands like in pure acrylate latex films.

\section{Introduction}

A latex ${ }^{1}$ is a colloidal suspension of submicronic polymer particles stabilized thanks to surfactant molecules localized on the surface of the particles. Synthetic latexes, polymerized in emulsion, were first developed to mimic natural rubber latexes in the late 40's. For health and environmental reasons, the range of applications of latexes produced by emulsion polymerization processes has broadened and among other uses they are a successful alternative to solvent-borne binders for coatings. However, solvent-borne binders such as alkyd resin still show superior properties in particular for exterior paints. After the solvent evaporation from alkyd solution, an oxidative drying occurs based on a free-radical chain mechanism in presence of $\mathrm{O}_{2}$ (from ambient air) and catalyzed by metal complexes leading to a crosslinked binder with interesting properties and durability. Waterborne aqueous dispersions of alkyd resins have also been prepared by dissolving a surfactant in the resin at high temperature before water addition and cooling under agitation ${ }^{2,3}$. This process led to stable emulsions of partially crosslinked alkyd droplets, however the drying time was too long for a wide commercial use. Nabuurs et al. ${ }^{4}$ attempted to synthesize waterborne acrylic-alkyd hybrids by means of emulsion polymerization of acrylate monomers in the presence of alkyds, but low monomer conversion and increasing phase separation as polymerization proceeded was observed.

As an alternative, it was proposed to synthesize acrylic-alkyd hybrid latexes in order to combine the advantages of both phases. Wang et al. ${ }^{5}$ first synthesized acrylic-alkyd hybrid latexes by miniemulsion polymerization. Miniemulsion polymerization allows the incorporation of water insoluble components into polymer particles because mass transfer 
through the aqueous phase is avoided ${ }^{6-8}$. Surfactants play a key role in the stabilization of the miniemulsions and the latexes produced from them. Thus, it has been reported that during the miniemulsification process the strength of the surfactant adsorption affects the mobility of the surfactant and hence its ability to stabilize the newly formed small droplets ${ }^{9}$. In addition, the localization of the surfactant in the film has a strong effect on the application properties. Thus, surfactant migration reduces gloss ${ }^{10,11}$ and adhesion ${ }^{12,13}$ when it accumulates on the film surface and increases water sensitivity when it forms aggregates inside the film ${ }^{14,15}$. Kientz et al ${ }^{16}$ listed three primary locations for surfactants upon film formation: (i) surfactant dissolution in the polymer, (ii) formation of a continuous membrane at the internal polymer/polymer interfaces and (iii) formation of islands of surfactant throughout the film and interfaces (film/air and film/substrate), which have been determined using numerous techniques: Fourier Transform Infra Red - Attenuated Total Reflection ${ }^{17}$, Atomic Force Microscopy ${ }^{18-20}$, Energy Filtering Transmission Electron Microscopy ${ }^{21}$ and freeze fracture ${ }^{22}$, Rutherford Backscattering ${ }^{20}$. However most of the reported results concern model acrylic or polystyrene latex films and to our knowledge no information concern hybrid systems. Besides, it might be interesting to observe the surfactant localization in the latex prior to film forming process. Surfactant migration depends on its adsorption strength on the surface of the polymer particles ${ }^{23,24}$, which for a particular surfactant depends on the characteristics of the particle surface. Consequently, the fact that the hybrid acrylic-alkyd systems are multiphase particles may affect surfactant migration. This is a topic which has not been treated in literature.

Thus, this paper presents the study of surfactant location in acrylic-alkyd systems using a Scanning Transmission Electron Microscopy setup in an Environmental Scanning Electron Microscope (STEM-in ESEM). This technique presents the advantage of enabling the observation of polymeric samples at lower voltage than classical Transmission Electron 
Microscopy (TEM) with good resolution and contrast. Moreover, a recent imaging configuration was developed for the observation of nanoparticles in water suspensions (wet$\mathrm{STEM}^{25}$ ). Given the novelty of such types of STEM imaging in ESEM, the understanding of the contrasts required a preliminary study of a model latex system. Thus, the first part of this paper is devoted to the imaging of the location of surfactant molecules in latex and after film forming process in a model pure acrylate copolymer latex. Then, in the second part, acrylicalkyd hybrid latexes with alkyds with different hydrophobicity level - i.e. which display two different morphologies- are studied. The surfactant localization in these materials is discussed in relation to their recipes and their morphologies.

\section{Experimental methods}

\section{Materials.}

Technical grade monomers, methyl methacrylate (MMA) and butyl acrylate (BA), supplied by Quimidroga, and acrylic acid (AA) supplied by Aldrich were used without purification. Two kinds of alkyd resin were employed, SETAL 293-XX (hydrophobic, so called HPB) and 1630WP-292 (hydrophilic, so called HPL), both supplied by Nuplex resin. The HPL alkyd resin contains more hydroxyl groups than the HPB one which makes it more hydrophilic. Both alkyds were synthesized by step-growth polymerization and differ by their acid values (HPB: $11 \mathrm{mg} \mathrm{KOH} \mathrm{/} \mathrm{g;} \mathrm{HPL:} 21 \mathrm{mg} \mathrm{KOH} \mathrm{/} \mathrm{g)} \mathrm{but} \mathrm{have} \mathrm{similar} \mathrm{molecular} \mathrm{weight}$ (HPB: $\mathrm{M}_{\mathrm{n}}=2800 \mathrm{~g} \cdot \mathrm{mol}^{-1}$ and HPL: $\mathrm{M}_{\mathrm{n}}=2500 \mathrm{~g} \cdot \mathrm{mol}^{-1}$ ). Stearyl acrylate (Aldrich) and behenyl acrylate (Norsocryl from Arkema) were used as costabilizers, and Dowfax 2A1 (alkyldiphenyl oxide disulfonate, Dow Chemicals) as surfactant. Potassium persulfate (KPS, Panreac), tert-butyl hydroperoxide (TBHP, Panreac), and ascorbic acid (AsAc, Panreac), were used as initiators. $\mathrm{NaHCO}_{3}$ was employed to control the miniemulsion viscosity by reducing electrostatic interactions between droplets. Distilled water was used throughout the work. 


\section{Miniemulsification}

All miniemulsions contain $50 \%$ of solids content, $50 \%$ (wbop, weight based on organic phase) of alkyd resin, $6 \%$ wbop of active surfactant, $4 \% \mathrm{wbm}$ (weight based on main monomers) of stearyl acrylate, and $\mathrm{NaHCO}_{3}$ at a water concentration of $0.039 \mathrm{M}$. The miniemulsion was produced as follows. First, the organic and the aqueous phases were mixed by magnetic stirring (10 min. at $1000 \mathrm{rpm})$. Then, the coarse emulsion was sonified with a Branson 450 equipment (15 min., power 9 and 80\% duty cycle). Finally, the miniemulsion was subjected to 6 cycles in a Niro-Souvi (model NS 1001L Panda) two-valve high-pressure homogeniser with pressures of 410 bar and 41 bar in the first and second valve, respectively.

\section{Polymerization and post-polymerization processes}

Polymerization reactions were carried out in batch in a $1 \mathrm{~L}$ glass reactor equipped with reflux condenser, stirrer, sampling device, and nitrogen inlet. Reaction temperature $\left(70{ }^{\circ} \mathrm{C}\right)$ was set constant by controlling the temperature of the fluid in the jacket by means of a thermostatic bath and a heat exchanger. The miniemulsion was added to the reactor and kept under stirring and nitrogen atmosphere (12-15 $\mathrm{mL} / \mathrm{min})$. KPS was added into the reactor after the miniemulsion reached the reaction temperature.

During post-polymerization the two components of the redox pair (TBHP/AsAc) were independently fed during $90 \mathrm{~min}$ to the reactor at $70^{\circ} \mathrm{C}$. Finally, the reaction was allowed to continue 30 min in batch. Two latexes were prepared, each one using either the HPL or the HPB alkyd resin. The average particle size measured by DLS (Dynamic Light Scattering) was $100 \mathrm{~nm}$ for both latexes.

The choice of the hydrophobicity level of the alkyd resin enabled to tailor the nanostructure of the latex particle. Indeed, in the case of the most hydrophilic alkyd resin (HPL), the external 
area of the latex particle is enriched in alkyd resin. This was clearly demonstrated by TEM and AFM observations ${ }^{26}$. Conversely, with the most hydrophobic alkyd resin (HPB), it was shown that the external area of the latex particle is enriched in acrylate.

An acrylic latex (blank latex) was synthesized as reference. This system was a 50\%wbop solid content latex based on a P(MMAcoBA) (50/50). The latex was synthesized with $2 \%$ wbop active surfactant, $4 \%$ wbop costabilizer (behenyl acrylate) and $0.5 \%$ wbop KPS as initiator. The monomers and the co-surfactant were mixed by magnetic stirring. The resulting preemulsion was further sheared by sonication with a Branson sonicator for $15 \mathrm{~min}$ then transferred in a four-neck reactor. The polymerization was started by the injection of a $5 \mathrm{~mL}$ solution of initiator and the reaction was done at $70^{\circ} \mathrm{C}$ for 3 hours under nitrogen flow. The average particle size measured by DLS was $180 \mathrm{~nm}$.

\section{Imaging technique: STEM-in-ESEM and wet-STEM.}

New developments in imaging techniques in ESEM enables the observation of nano-objects in suspensions in a Scanning Transmission Electron Microscopy configuration (wet-STEM)

25. A homemade device holds the sample grid between the electron gun and the annular backscattered Electron (BSE) detector placed underneath the sample grid. The observation of latex in water is made possible by the addition of a thermoregulated plate (Peltier plate): liquid state of water can be maintained in the microscope chamber by adapting temperature and pressure (for instance, at $2^{\circ} \mathrm{C}$, vapor pressure is around 5 Torr). The BSE annular detector is placed at a distance of $7 \mathrm{~mm}$ to the sample and centered on the electron beam axis so that electrons from the direct beam are not collected. Under these conditions, observations are performed in annular dark field imaging conditions (basically, brightest contrast is given for high atomic mass and thick materials). Under those conditions, the collection angle range of 
the detector is 420 to $820 \mathrm{mrad}$. This observation setup is adequate for the imaging of latexes in water and polymer thin films (few hundred nanometers thick). Hereafter, images taken in the presence of liquid water in the sample are described as wet-STEM images. When liquid water is evaporated, the term STEM-in-ESEM is chosen.

A drop of diluted latex is spread on a holey carbon coated grid before being observed. The evaporation of water is controlled in-situ until obtaining a water layer thin enough to allow the imaging. The experiments are performed in an Environmental Scanning Electron Microscope ESEM XL30 FEG from FEI Company. All images are taken at an accelerated voltage of 30keV. Additional Energy Dispersive X-Ray Spectroscopy (EDXS) are performed using an EDX detector at an accelerated voltage of $30 \mathrm{keV}$ under high vacuum conditions.

\section{Numerical approach of image contrasts.}

Modeling of image contrasts in STEM that simulates the experimental configuration has been investigated. A specific software based on a Monte-Carlo method (Hurricane ${ }^{27}$ ) is used to calculate the path of 100000 electrons across a modeled thin film. From this, the amount of electrons collected in the 420 to $820 \mathrm{mrad}$ collection angle range is then calculated. The software setup enables the choice of geometry, composition, detector and electron beam conditions. The sample composition is specified through atoms ratio and density (table 1), considerations of bonds or charges were not available. Thus for Dowfax 2A1 surfactant, several cases are considered. First, the compound "Dowfax" is simply based on the chemical formula. The compound "Dowfax tail" is attributed to the hydrocarbon tail (hydrophobic tail) and the compound "Dowfax head" is attributed to the sulfonated heads (hydrophilic heads) considered as $\mathrm{NaHSO}_{3}$ crystals. Both alkyd resins considered here are long-oil alkyd resins. For the calculations, the HPB alkyd resin is considered as a classical alkyd resin based on the polymerization of one mole of an unsaturated fatty acid containing 23 carbon atoms, with one 
mole of phtalic anhydride and one mole of glycerol. The HPL alkyd resin is based on the same formula with the addition of one mole of hydroxyl groups. In all calculations, the carbon coat layer of the observation grid is not considered.

Table 1: Input values for the simulation run on Hurricane software.

\begin{tabular}{|c|c|c|c|c|c|c|}
\hline \multirow[t]{2}{*}{ Compound } & \multicolumn{5}{|c|}{ molar ratio of each constitutive atom } & \multirow[t]{2}{*}{ density } \\
\hline & $\mathrm{C}$ & $\mathrm{H}$ & $\mathrm{O}$ & $\mathrm{Na}$ & $\mathrm{S}$ & \\
\hline Water & & 2 & 1 & & & 1 \\
\hline P(MMA-co-BA) copolymer & 12 & 16 & 4 & & & 1 \\
\hline Alkyd HPB & 34 & 60 & 8 & & & 1 \\
\hline Alkyd HPL & 34 & 61 & 9 & & & 1 \\
\hline Dowfax & 24 & 24 & 7 & 2 & 1 & 1.2 \\
\hline Dowfax head $\mathrm{NaHSO}_{3}$ & & 1 & 3 & 1 & 1 & 1.5 \\
\hline Dowfax tail $\left[\mathrm{CH}_{2}\right]_{\mathrm{n}}$ & 1 & 2 & & & & 1 \\
\hline
\end{tabular}

\section{Results and Discussion}

\section{Preliminary study: localization of surfactant molecules in model acrylate latex}

Given the novelty of the environmental-STEM setup for the imaging of colloidal systems, this first part aims at demonstrating its ability to image surfactant in acrylic system both wet and dry conditions. To do so, a model acrylic latex stabilized with Dowfax 2A1 surfactant is observed using the wet-STEM imaging setup (Figure 1a) at $2^{\circ} \mathrm{C}$ and 5.6Torr water vapor pressure. Fairly monodisperse spherical particles are observed since the particle deformation is avoided by an observation below the glass transition temperature (around $15^{\circ} \mathrm{C}$ ). In addition, bright areas surround these particles. The same model acrylate latex is observed in dry conditions (STEM-in-ESEM, $2^{\circ} \mathrm{C}$ and 3.9Torr water vapor pressure) and no bright crowns are visible around the latex particle (Figure 1b). Finally, Figure 1c shows this same model latex after slow water evaporation in order to favor the gathering and compaction of the particles. Note that the latex particles manage to deform despite the low temperature. This is due to the fact that minimum film formation temperature does not only depend on glass 
transition temperature but also on particle $\operatorname{size}^{28}$ and water evaporation rate. This image is different from Figure $1 \mathrm{~b}$ in that brighter edges are obtained. Reminding that the images follow a mass-thickness contrast in which high atomic mass atoms appear brighter as well as thicker materials. In Figure 1c, under particle compaction, the edges of the particles deform. Thus, the amount of material that is interacting with the electron beam is larger for the case of deformed edges compared to non-deformed edges. In addition, one can intuitively consider that when the water evaporated the Dowfax 2A1 layer adsorbed on the latex particles might re-organize and gather toward the inter-particle area and thus, could influence the brightness of these thickened edges. Finally, the slow evaporation could lead to the presence of trapped water between the particles leading to a higher electron emission field. Indeed, in Figure 6, Hurricane simulations show that, for a given thickness, the electron scattering of water ("water") and Dowfax 2A1 ("dowfax") is larger than the one of the acrylic copolymer (“copolymer”).

From Figure 1a, a grey value profile of a $180 \mathrm{~nm}$ diameter particle is plotted on Figure 2. The measured thickness of the bright crown is around 50nm. This thickness range is not consistent with the thickness range of the surfactant layer adsorbed on the latex particle which should be no more than a few nanometers. However due to the fact that these bright areas are specifically located around the latex particle, it is reasonable to consider that the surfactant layer plays a role in this artifact. It is also reasonable to consider that the presence of water during the imaging might play a role in this artifact. Indeed, previous studies focused on the effect of radiation damage in environmental scanning electron microscopy (ESEM) ${ }^{29}$ showed that water acts as a source of small, highly mobile free radicals, which accelerate specimen degradation. Moreover, they found an increase in the quantities of reactive species produced with increasing beam energy. For primary electrons of $25 \mathrm{keV}$, the reactive species spread over a wider region and their decay is slower. 

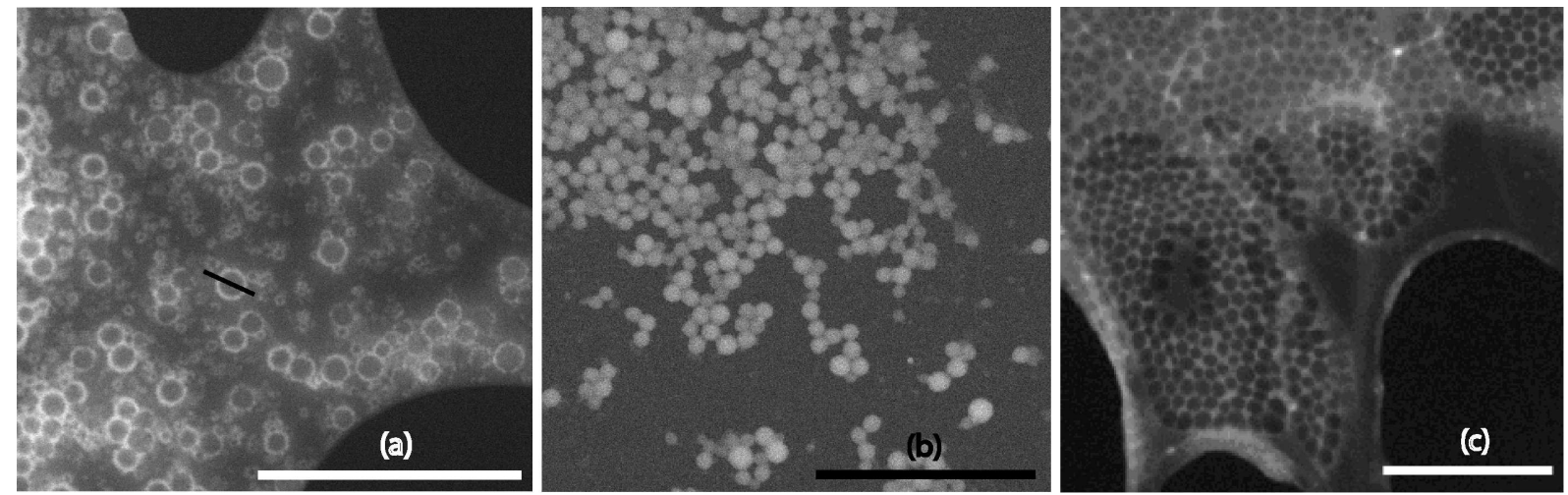

Figure 1: scale bar: $2 \mu \mathrm{m}$. (a) wet-STEM image of the model acrylate latex in suspension $\left(2^{\circ} \mathrm{C} / 5.6 \mathrm{~T}\right.$ orr). (b) STEM-in-ESEM image of the model acrylate latex after fast evaporation of water $\left(2^{\circ} \mathrm{C} / 3.9\right.$ Torr $)$. (c) STEM-in-ESEM image of the model acrylate latex right after slow water evaporation $\left(2^{\circ} \mathrm{C} / 5.3\right.$ Torr $)$. Note that the large black areas correspond to the holes in the carbon coated grid.

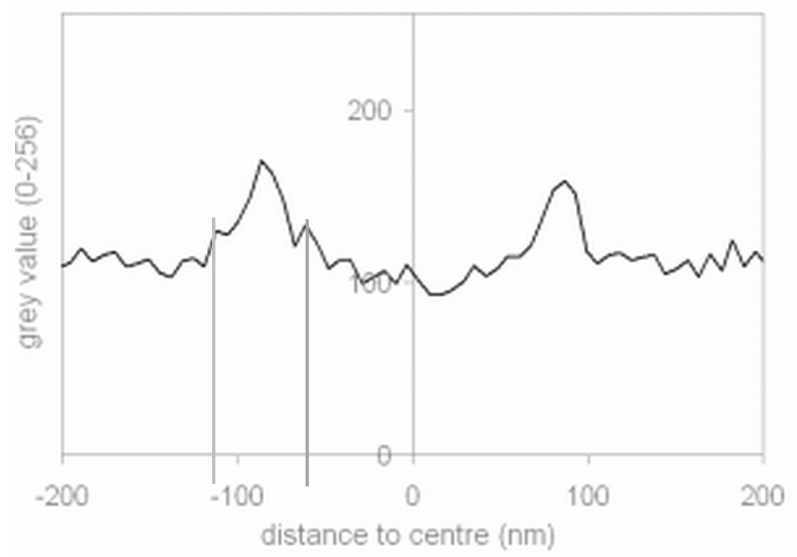

Figure 2: Grey value profile of a latex particle observed in wet-STEM conditions (depicted on Figure 1a)

Thus water radiolysis is likely to occur during wet-STEM observations of latexes leading to the creation of short-lived free radicals $\mathrm{H} \bullet$ and $\mathrm{HO} \bullet{ }^{29}$. In addition, Dowfax 2A1 molecules 
(Figure 3) might also undergo homolytic bond cleavage due to the weakness of the C-S bond ${ }^{30}$. Contrary to short-lived water radicals, this bond cleavage would lead to long-lived radicals due to sterical effect of phenyl groups hindering the approach of another radical ${ }^{31}$. In addition, these radicals can undergo further Single Electron Transfer under the electron beam. Therefore, negative charge accumulation is likely to occur on the surface of the latex particles leading to a larger electron emission fields from those charged areas, explaining the presence of the bright crowns. In dry conditions, no water radiolysis is occurring, thus this artifact is not observed.

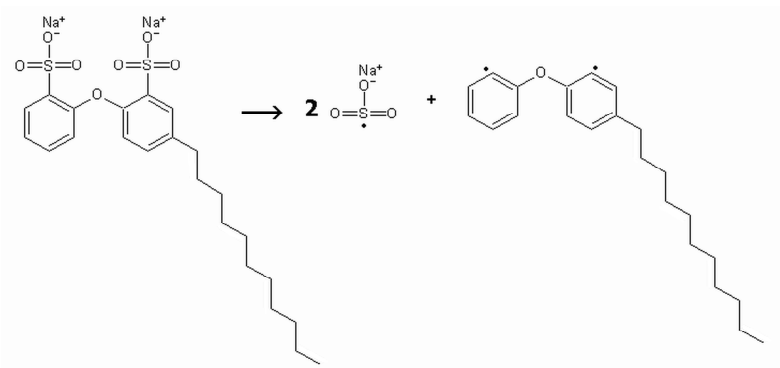

Figure 3: Formation of long-lived radicals from the Dowfax 2A1 molecules under electron beam from homolytic cleavage of the weak C-S bond.

As an attempt to model the behavior of the electron scattering field through the latex particle with and without the presence of water, a mathematical model based on a Monte-Carlo method (Hurricane software) has been used. A Hurricane simulation based on a pure copolymer latex particle and two other calculations considering an additional shell of either "Dowfax" or "NaHSO 3 " are depicted in Figure 4a (see Experimental section for more details). In the case of the "NaHSO 3 " shell, this sample geometry is an attempt to describe the specific ordering of surfactant molecules into a layer around the latex particle. As expected the scattering of the latex particle is consistent with a mass and thickness contrast. However, no 
effect is observed from the presence of a "surfactant shell" (whatever the shell composition). Similar calculations made with an additional 100nm-thick water layer are depicted in Figure 4b. A flat plot is observed for the pure copolymer latex particle immersed in water as well as for the latex with a "surfactant shell". The absence of contrast between the internal area of the particle and the water is consistent with the corresponding grey levels in Figure 2. Thus an electron scattering is obtained from the presence of water but none of these calculations manage to describe the peculiar phenomenon of bright crowns observed in Figure 1a. This supports the idea that charges accumulation is involved in the observed contrast.
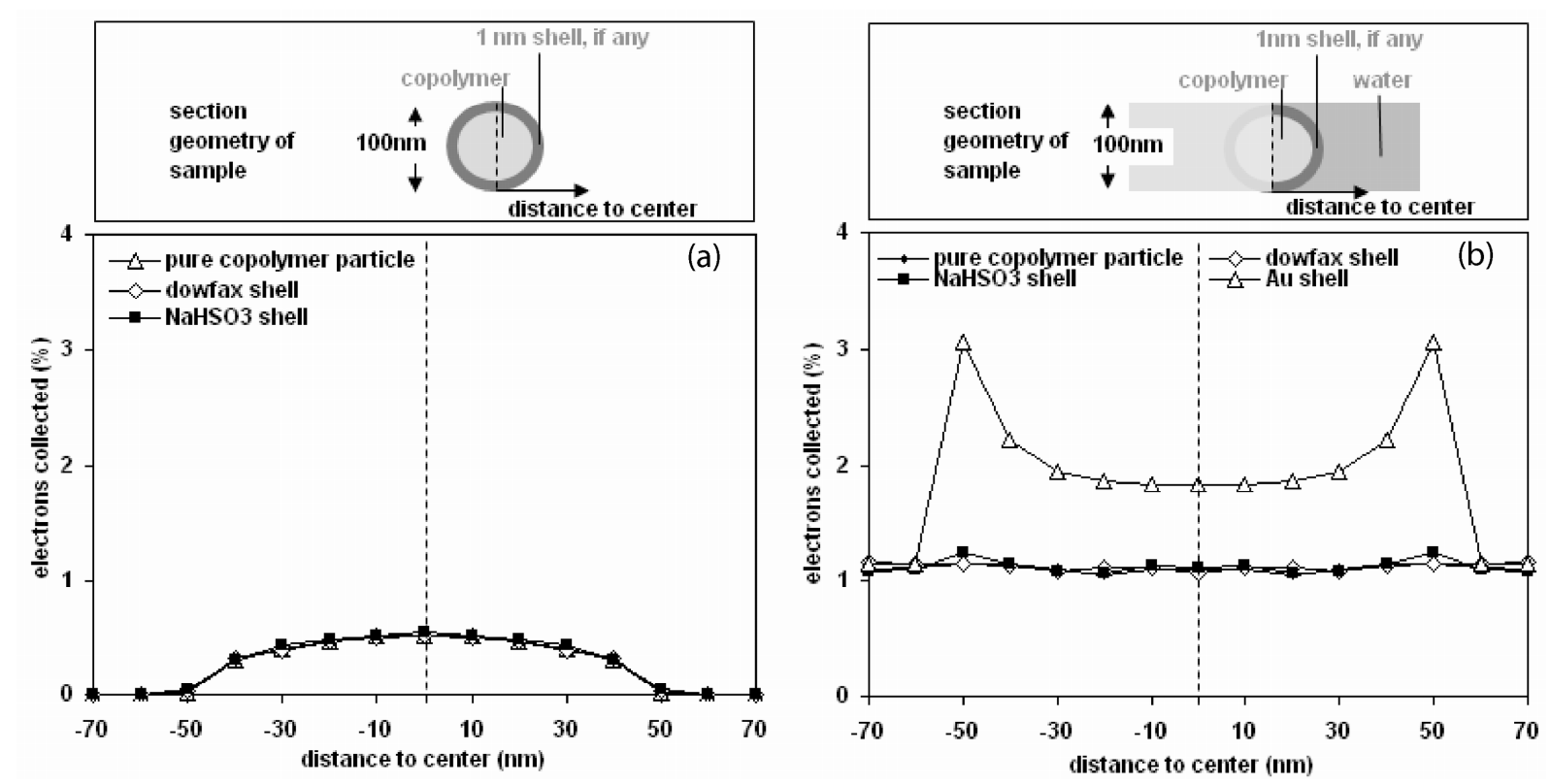

Figure 4: (a) Hurricane simulation of a copolymer latex particle (100nm diameter) with and without a shell attributed to the surfactant layer. (b) Hurricane simulation of a copolymer latex particle immersed in a 100nm thick water layer (100nm diameter) with and without shell attributed to the presence of the surfactant layer.

In an attempt to simulate this phenomenon, another calculation with Hurricane is performed. Nevertheless, as the software does not allow simulation of charging effects, the additional 
charges that lead to a deviation of the electrons are assimilated to a highly diffusive compound $(\mathrm{Au})$. Thus, an additional Hurricane simulation is done considering a core-shell particle comprising a copolymer core and a $1 \mathrm{~nm}$ thick shell of Au (Figure 4b). Under these conditions, the scattering profile shows two "bright" peaks appearing at distance to the centre equal to the particle radius. Thus, this simulation confirms that the presence of a scattering compound at the only surface of the particle is enough to create the bright artifact such as the bright crown observed around the latex particle.

Charge Contrast Imaging ${ }^{32}$ is a recent technique in ESEM that take advantage of the variations of charge accumulations at the surface of a sample to create image contrast. Similarly, in our wet-STEM observations, the Dowfax 2A1 layer adsorbed on the surface of the latex particles is highlighted through the formation of charge accumulation at the surface of the particles due to the presence of both the surfactant layer and the water. Thus, even if the thickness of the surfactant layer is below the resolution of the experimental observation conditions, wet-STEM appears as a powerful technique to detect its presence.

The other information provided by theses images, is that when water evaporation is fast, neither surfactant aggregates nor surfactant layers are detected. Conversely, as already shown in Figure 1c, using slow water evaporation promotes the latex particle gathering and compaction, i.e. enables to mimic film forming process. In that case, the surfactant localization can also be studied to address its outcome in the film. Thus, the imaging of surfactant molecules after film forming process in the model acrylic latex is performed using STEM-in-ESEM setup. 
After storage in a clean grid box at room temperature for a month, the same area shown in Figure 1c is observed again and presented in Figure 5a. Bright lumps clearly formed throughout the film and surprisingly, the copolymer particles remain in shape even during the storage above the copolymer glass transition temperature. This non-deformation of the particle during the storage is likely due to interactions between the acrylate copolymer and the electron beam during the first exposure (Figure 1c). The radicals that formed under the electron beam can react together and form covalent bonds between the polymer chains ${ }^{33}$ leading to cross-linking of the material and hindering the particle deformation even above the glass transition temperature. Due to this degradation phenomenon, two successive observations of a same area would not be significant of the real latex behavior upon film formation. Another area is presented in Figure 5b, in that case, the film formation process did occur and the particle edges are not visible anymore. Moreover, like in figure 5a, bright objects are visible, more particularly around the carbon coat holes.
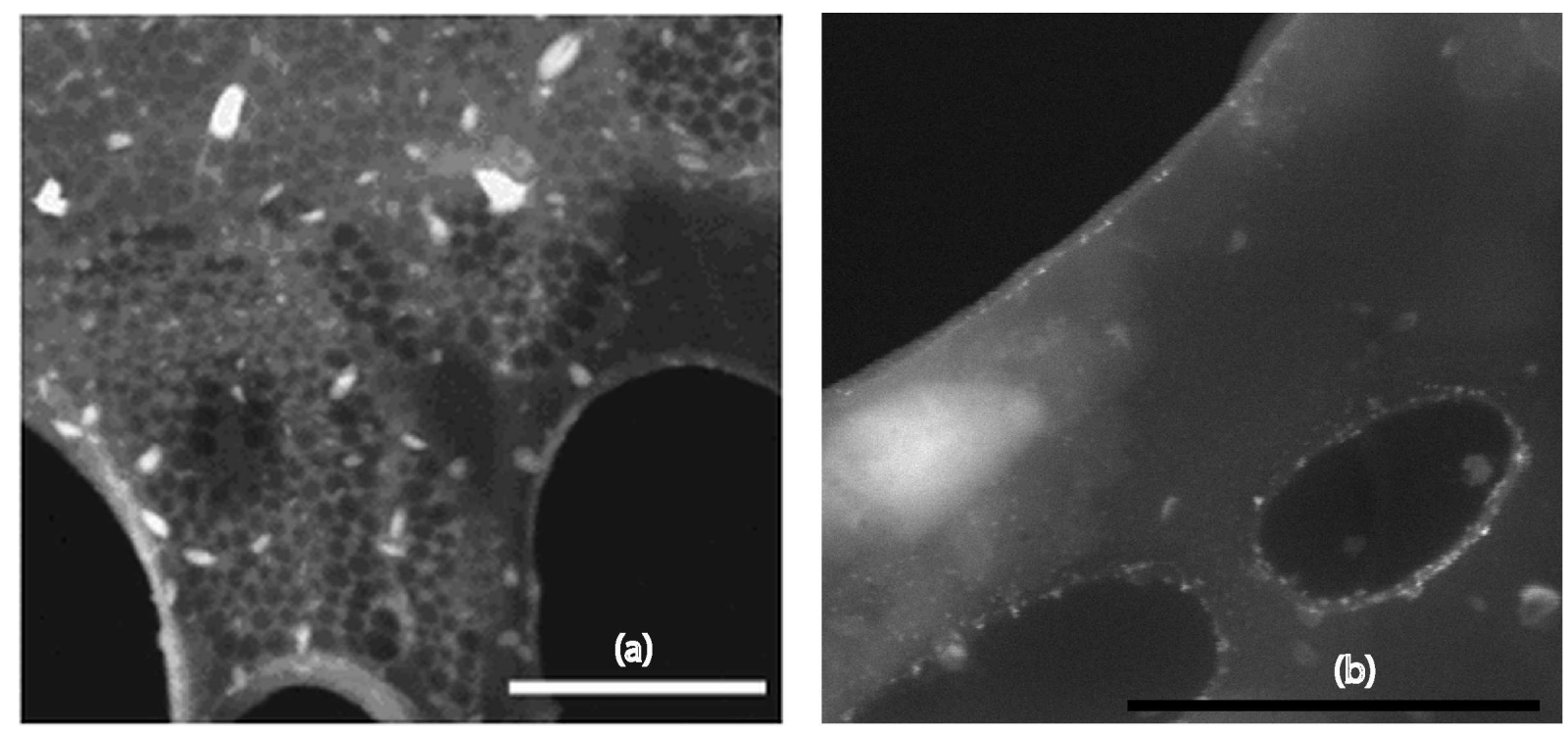

Figure 5: Scale bar $2 \mu \mathrm{m}$ (a) STEM-in-ESEM image $\left(2^{\circ} \mathrm{C} / 2 \mathrm{~T}\right.$ orr $)$ of the same area than Figure 1c, after storage at Room Temperature. (b) STEM-in-ESEM image $\left(2^{\circ} \mathrm{C} / 2 \mathrm{Torr}\right)$ of acrylate film after storage at Room Temperature. 
In these images of latexes after film forming process, no water is remaining: thus, bright artifacts from water radiolysis cannot be responsible for those bright lumps. Hurricane simulations are performed to compare the electron scattering behavior of each compound present in our system. A monolayer (from 0 to $100 \mathrm{~nm}$ thick) of each compound is considered. To describe a specific ordering of surfactant molecules that would lead to close packing of the hydrophilic heads together, a layer of $\mathrm{NaHSO}_{3}$ ("Dowfax head") is also considered. Similarly a layer of "Dowfax tail" is also depicted. In addition, the scattering behavior of alkyd resins is calculated. As shown in Figure 6, "Dowfax tail", both alkyd resins and acrylate copolymer have similar scattering behavior. Consistently with a mass-thickness contrast, the largest amount of electrons collected is obtained for "Dowfax head" and "Dowfax", which means that the later will appear as the brightest materials. This suggests that the bright objects in figure 5 are likely made of these compounds.

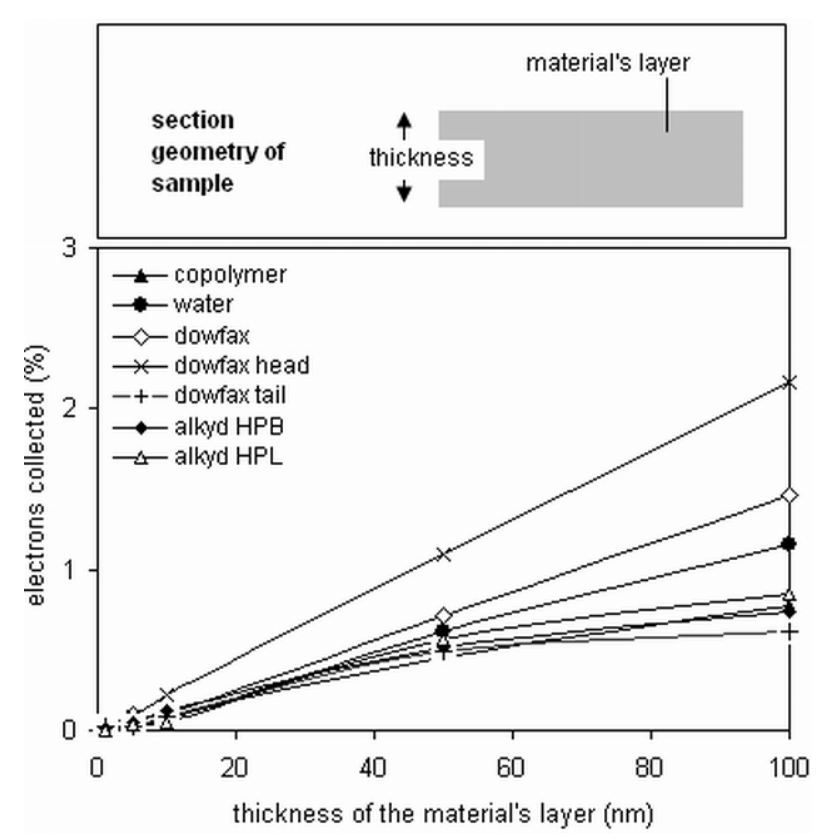

Figure 6: Hurricane Simulation: Electrons collected vs. increasing thickness of a layer of material. 
To confirm that surfactant molecules gather into lumps, a solution of surfactant in water is evaporated on a grid and observed in STEM-in-ESEM. Bright dots can be observed on the image: surfactant molecules seem to rearrange into highly diffusive objects of tens of nanometers size (Figure 7).

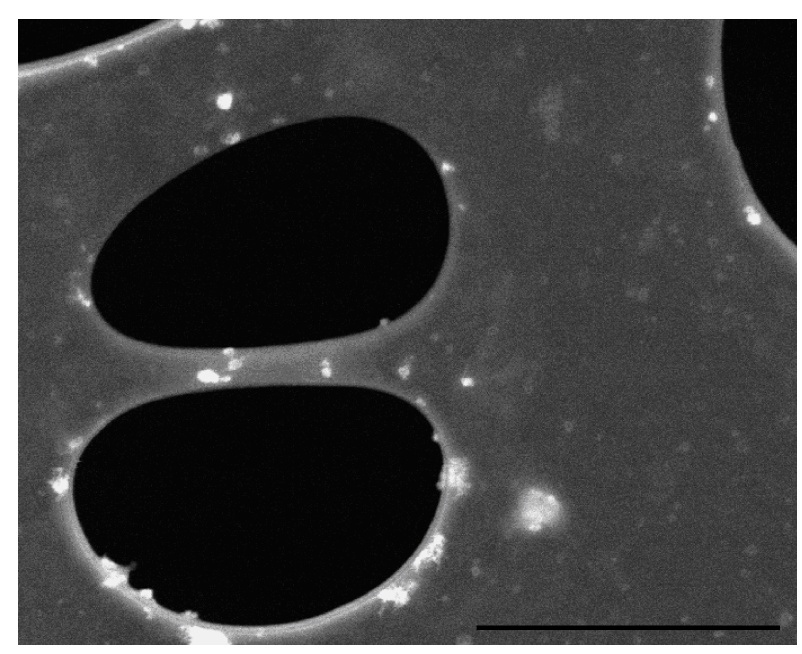

Figure 7: STEM-in-ESEM image of surfactant mixed in water after evaporation of water. Scale bar $2 \mu \mathrm{m}$

In addition, Energy Dispersive X-Ray Spectroscopy is performed on the acrylate model sample observed in Figure 5. Both bright lumps and grey latex particles are characterized; the analyzed area is $100 \mathrm{~nm} \times 100 \mathrm{~nm}$ and its localization is depicted on the image (Figure 8). In Figure 8a, the EDX spectrum of a bright lump is presented while in Figure 8b, the EDX spectrum of a grey domain (latex particle) is presented. The following elements are detected in both areas: Carbon $(\mathrm{C})$ and Oxygen $(\mathrm{O})$ come from the polymer and the Carbon coated grid, Copper $(\mathrm{Cu})$ from the Copper TEM grid and Silicium ( $\mathrm{Si}$ ) comes from the detector. Besides those elements, Sodium (Na) and Sulfur (S) are detected in the bright areas whereas 
none is detected in the dark ones. This confirms that a large amount of Dowfax 2A1 is gathered in the bright lumps while few remains adsorbed on the surface of the latex particles.
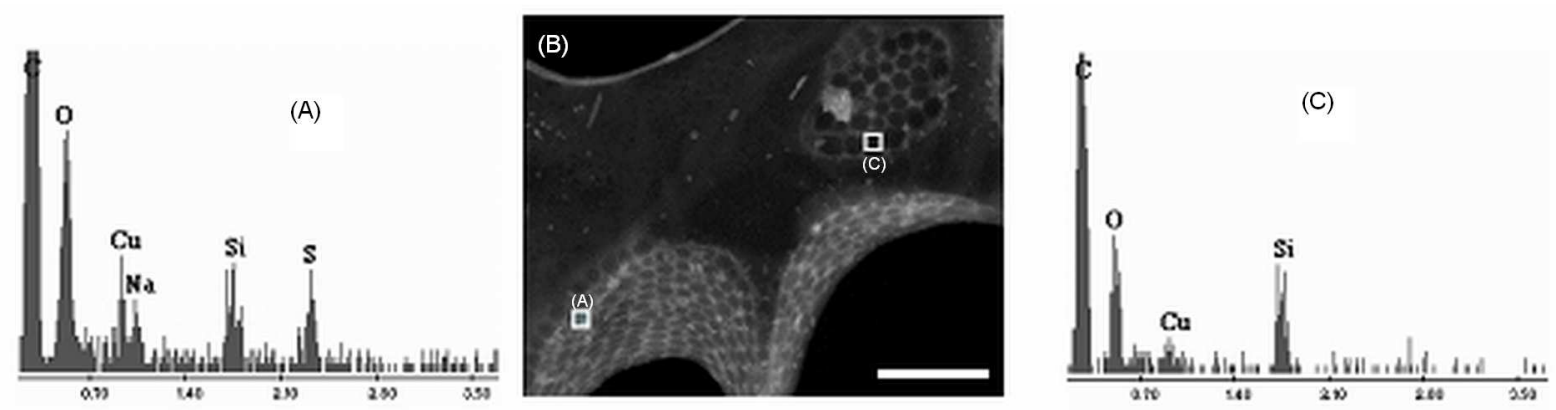

Figure 8: EDXS analysis of bright (A) and dark (C) domains of STEM image (B). scale bar $1 \mu \mathrm{m}$

These observations and modeling runs comfort the assumption that specific surfactant molecules ordering (coming after surfactant migration induced by water evaporation) are responsible for their surprising electron scattering in dry films.

To conclude, this first part clearly demonstrates that in pure acrylate latexes, surfactant molecules are gathering into nano-to-microscale islands throughout the film. In STEM configuration, these aggregates of Dowfax 2A1 molecules are characterized by a bright contrast compared to the contrast attributed to the acrylate copolymer. In the following, this specific electron scattering behavior of surfactant molecules in environmental STEM observations is used to provide insights on the surfactant localization in two hybrid alkyd/acrylate latex films with different hydrophobicity levels of the alkyd resin.

\section{Surfactant outcome in alkyd/acrylate hybrid latexes after film forming process}


Due to their glass transition temperature below $0^{\circ} \mathrm{C}$ (for the model acrylate latex, the glass transition temperature is around $15^{\circ} \mathrm{C}$ ), the film formed from hybrid latexes at room temperature and even at $2{ }^{\circ} \mathrm{C}$ (experimental conditions of the preliminary study). Thus, the particle coalescence occurs very early during the water evaporation and isolated undeformed particles are not obtained even in wet-STEM. However, surfactant outcome after film forming process can be studied in dry state. Figure 9a and 9b are STEM-in-ESEM images of films obtained from hybrid latexes based on the HPB and HPL resins, respectively. The image obtained with the film of the HPB alkyd resin/acrylate latex (Figure 9a) presents similarities with the image of model acrylate latex after film formation (Figure 5b): it shows a continuous grey background due to the film forming process of the latex with bright objects similar to surfactant lumps. In this latex, the alkyd resin is located inside the latex particle and so the surfactant molecules should mainly interact with the acrylate copolymer. As plotted in Figure 6, the scattering of acrylate copolymer and alkyd resin are similar, therefore no difference in scattering contrasts are expected in the image of mixed films. Thus, it can be concluded that during film forming process, the exudation of surfactant in this hybrid latex occurs just like in pure acrylate copolymer latex.

In Figure 9b, the "background" is not homogeneous as in Figure 9a but comprises two distinct contrasts in similar ratio. A light grey phase with needle shape is visible on a darker grey domain. In addition, brighter objects, similar to surfactant lumps are also present, similar to the ones visible in Figure 9a. The causes of the background heterogeneity could be found in the fact that with hydrophilic alkyd based latex, the alkyd resin is likely outside the particle, i.e. in contact with the surfactant molecules. Taking into account that alkyd resin comprises long hydrocarbon chains of fatty acids, it should have strong affinity with the surfactant hydrophobic tails ${ }^{34-36}$. The presence of the surfactant molecules associated with the alkyd resin in small domains can increase the overall electron scattering of these domains compared 
to pure alkyd resin or pure acrylate copolymer, leading to a brighter contrast. Thus the light grey phase could be attributed to alkyd resin associated with Dowfax 2A1 molecules while the brighter objects are likely surfactant lumps due to partial surfactant exudation. This partial exudation and the large amount of light grey phase in figure $9 \mathrm{~b}$ is a direct observation of the preferential interaction of the surfactant tail with the alkyd resin, and suggests that even prior to film forming process (during emulsification and polymerization), the hydrophobic tails are associating with the alkyd resin.
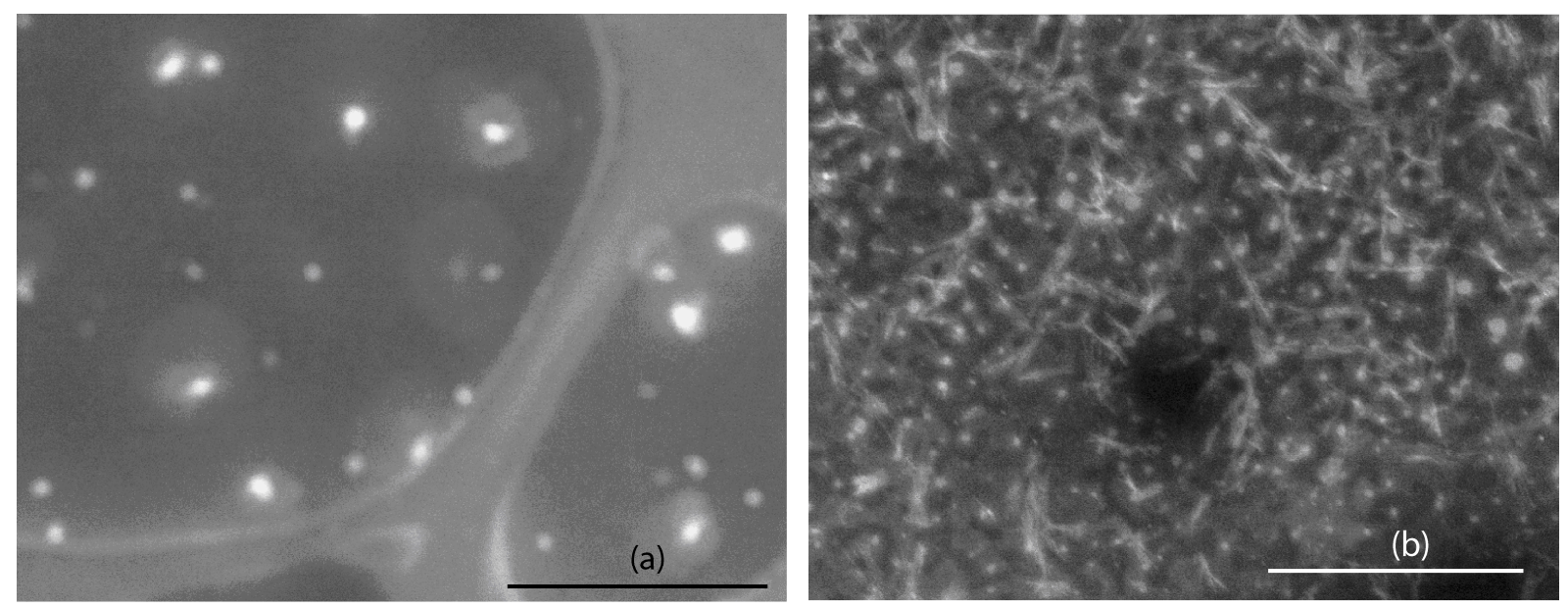

Figure 9: STEM image of hybrid acrylate latex: (a) with HPB resin (Scale bar 1 $\mu \mathrm{m})$; (b) with HPL resin (Scale bar $2 \mu \mathrm{m})$. Note the dark round shapes are the carbon coat holes.

To sum up, STEM observations of hybrid latexes highlights two different outcomes of the surfactant molecules. In the HPB case, exudation of the surfactant into islands is observed whereas in the HPL case the surfactant remains in interaction with the alkyd phase due to a strong affinity between the alkyd resin and the hydrophobic tails of the surfactant molecules. These conclusions are depicted in Figure 10. 


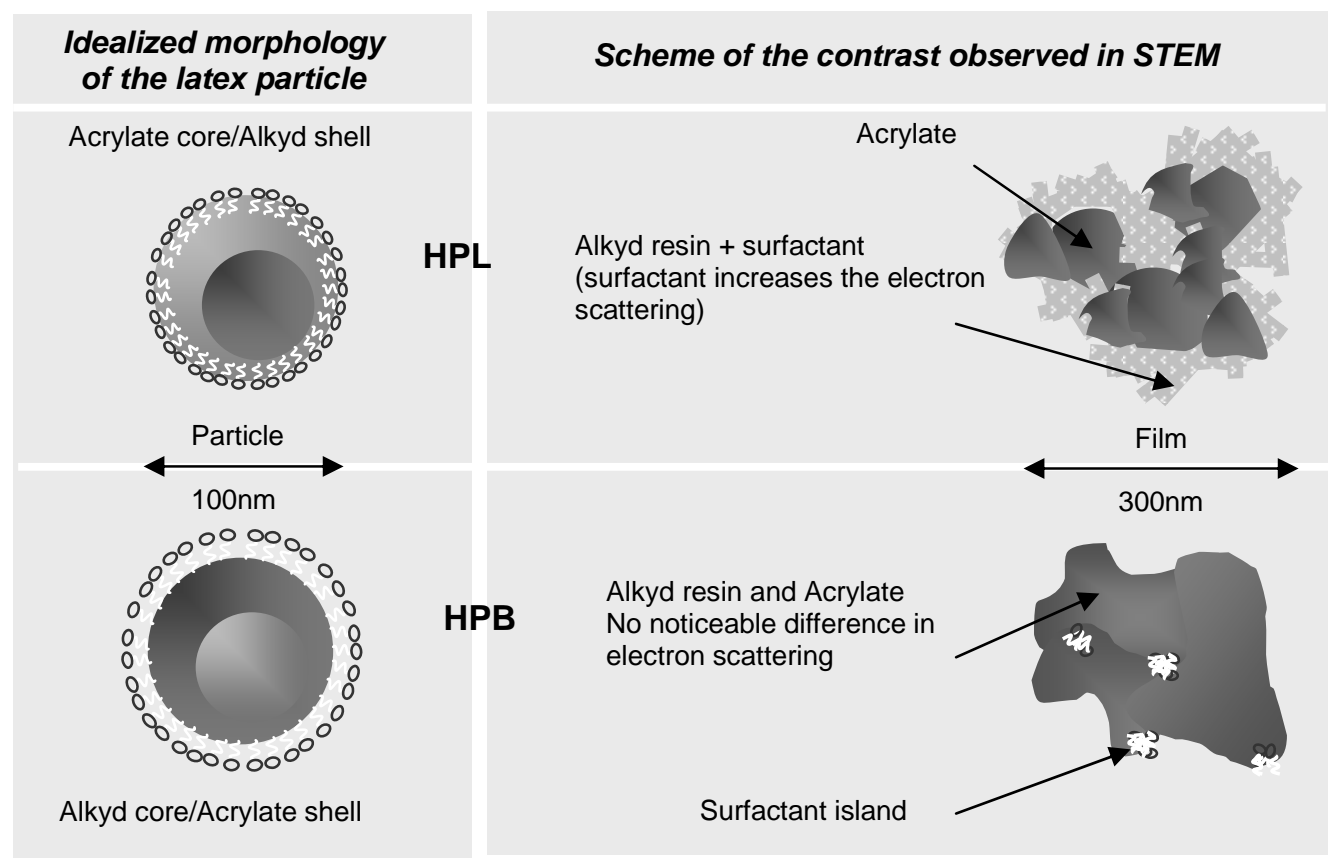

Figure 10: Scheme of the STEM observations of alkyd/acrylate hybrid latexes (left).

\section{Conclusion}

The recent development of imaging technique using a high angle annular dark field configuration enables a fine imaging of nanometric latexes in their colloidal state. This technique has been used in this work to observe the surfactant layer (Dowfax 2A1) adsorbed on surface of acrylate latex particles. Despite the fact that the thickness of the surfactant layer is below the resolution of the experimental observation conditions, its presence has been detected thanks to charge accumulation phenomenon at the surface of the particle. After film forming process, these surfactant molecules remain in the film in various locations depending on the film forming conditions and the interactions between the surfactant molecules and the polymer nature. In pure acrylate copolymer latex, these molecules preferentially gather into island throughout the polymer films. A similar result is obtained for hybrid latexes comprising a hydrophobic alkyd resin. In that case, the alkyd resin is mainly located in the internal domain of the latex particles surrounded by acrylate copolymer so the surfactant molecules 
are preferentially interacting with the acrylate phase. Different observations are made in the case of hydrophilic alkyd resin, in which such surfactant exudation into islands is only partial. In that case, the alkyd resin is preferentially located on the outside of the latex particles. Hydrophobic interactions between surfactant molecules and alkyd fatty chains hinder the mobility of surfactant molecules and so lead to a mixed phase containing both molecules. At last, these environmental observations of surfactant exudation in hybrid films enables direct insights on the specific interactions between the alkyd resin and the hydrophobic tails of the surfactant molecules. Thus, the study of surfactant outcome can give insights of the surfactant behavior during emulsification and polymerization step by highlighting specific interaction with the other component of the latex. For instance, a preferential burying of surfactant could hinder the formation of small droplets due to the fact that the surfactant molecules could not move fast enough to stabilize the newly formed droplets.

\section{Aknowledgements}

This work was funded by the EC Framework 6 Integrated Project, NAPOLEON, under contract No. IP 011844-2.

\section{Supporting Information Available}

This information is available free of charge via the Internet at http://pubs.acs.org/

\section{References}

1. Daniel, J.-C.; Pichot, C., Les latex synthétiques : Élaboration - Propriétés Applications. 2006.

2. Ostberg, G.; Bergenstahl, B., Emulsification of alkyds for industrial coatings. Journal of Coatings Technology 1996, 68, (858), 39-45.

3. Gooch, J. W., Emulsification and polymerization of alky resins. New york, 2002; p 248. 
4. Nabuurs, T.; Baijards, R. A.; German, A. L., Alkyd-acrylic hybrid systems for use as binders in waterborne paints. Progress in organic coatings 1996, 27, 163-172.

5. Wang, S. T.; Schork, F. J.; Poehlein, G. W.; Gooch, J. W., Emulsion and miniemulsion copolymerization of acrylic monomers in the presence of alkyd resin. Journal of Applied Polymer Science 1996, 60, 2069-2076.

6. Antonietti, M.; Landfester, K., Polyreactions in miniemulsions. Progress in Polymer Science 2002, 27, (4), 689-757.

7. Asua, J. M., Miniemulsion polymerization. Progress in Polymer Science 2002, 27, (7), 1283-1346.

8. $\quad$ Schork, F. J.; Luo, Y.; Smulders, W.; Russum, J. P.; Butté, A.; Fontenot, K., Miniemulsion polymerization. Advances in Polymer Science 2005, 175, 129-255.

9. Manea, M.; Chemtob, A.; Paulis, M.; de la Cal, J. C.; Barandiaran, M. J.; Asua, J. M., Miniemulsification in high-pressure homogenizers. Aiche Journal 2008, 54, (1), 289-297.

10. Lee, W. P.; Gundabala, V. R.; Akpa, B. S.; Johns, M. L.; Jeynes, C.; Routh, A. F., Distribution of surfactants in latex films: A rutherford backscattering study. Langmuir 2006, 22, (12), 5314-5320.

11. Al-Ghamdi, G. H.; David Sudol, E.; Dimonie, V. L.; El-Aasser, M. S., High PVC film-forming composite latex particles via miniemulsification, part 3: Optical properties. Journal of Applied Polymer Science 2006, 101, (6), 4526-4537.

12. Butler, N.; Fellows, C. M.; Gilbert, R. G., Effect of surfactants used for binder synthesis on the properties of latex paints. Progress in Organic Coatings 2005, 53, (2), 112118.

13. Charmeau, J. Y.; Gerin, P. A.; Vovelle, L.; Schirrer, R.; Holl, Y., Adhesion of latex films. Part III. Surfactant effects at various peel rates. Journal of Adhesion Science and Technology 1999, 13, (2), 203-215.

14. Butler, N.; Fellows, C. M.; Gilbert, R. G., Effect of surfactant systems on the water sensitivity of latex films. Journal of Applied Polymer Science 2004, 92, (3), 1813-1823.

15. Aramendia, E.; Barandiaran, M. J.; Grade, J.; Blease, T.; Asua, J. M., Improving water sensitivity in acrylic films using surfmers. Langmuir 2005, 21, (4), 1428-1435.

16. Kientz, E.; Holl, Y., Distribution of surfactants in latex films. Colloids and Surfaces aPhysicochemical and Engineering Aspects 1993, 78, 255-270.

17. Zhao, C. L.; Holl, Y.; Pith, T.; Lambla, M., FTIR-ATR spectroscopic determination of the distribution of surfactants in latex films. Colloid and Polymer Science 1987, 265, (9), 823829.

18. Juhue, D.; Wang, Y. C.; Lang, J.; Leung, O. M.; Goh, M. C.; Winnik, M. A., Surfactant exudation in the presence of coalescing aid in latex films studied by Atomic Force Microscopy. Journal of Polymer Science Part B-Polymer Physics 1995, 33, (7), 1123-1133. 19. Lam, S.; Hellgren, A. C.; Sjoberg, M.; Holmberg, K.; Schoonbrood, H. A. S.; Unzue, M. J.; Asua, J. M.; Tauer, K.; Sherrington, D. C.; Goni, A. M., Surfactants in heterophase polymerization: A study of film formation using atomic force microscopy. Journal of Applied Polymer Science 1997, 66, (1), 187-198.

20. Tzitzinou, A.; Jenneson, P. M.; Clough, A. S.; Keddie, J. L.; Lu, J. R.; Zhdan, P.; Treacher, K. E.; Satguru, R., Surfactant concentration and morphology at the surfaces of acrylic latex films. Progress in Organic Coatings 1999, 35, (1-4), 89-99.

21. DuChesne, A.; Gerharz, B.; Lieser, G., The segregation of surfactant upon film formation of latex dispersions: An investigation by energy filtering transmission electron microscopy. Polymer International 1997, 43, (2), 187-196.

22. Wang, Y. C.; Kats, A.; Juhue, D.; Winnik, M. A.; Shivers, R. R.; Dinsdale, C. J., Freeze fracture studies of latex films formed in the absence and presence of surfactant. Langmuir 1992, 8, (5), 1435-1442. 
23. Tadros, T., Polymeric surfactants in disperse systems. Advances in Colloid and Interface Science 2008, in press.

24. Karlson, L.; Olsson, M.; Boström, G.; Piculell, L., Influence of added surfactant on particle flocculation in waterborne polymer-particle systems. Journal of Coatings Technology Research 2008, 5, (4), 447-454.

25. Bogner, A.; Thollet, G.; Basset, D.; Jouneau, P. H.; Gauthier, C., Wet STEM: A new development in environmental SEM for imaging nano-objects included in a liquid phase. Ultramicroscopy 2005, 104, (3-4), 290-301.

26. Faucheu, J.; Goikoetxea, M.; Minari, R.; Asua, J. M.; Canetta, E.; Keddie, J. L.; Chazeau, L.; Gauthier, C., Innovative design of hybrid acrylate/alkyd latexes for coatings application. To be published.

27. SAMx Microanalysis Application Software http://www.samx.com.

28. Jensen, D. P.; Morgan, L. W., Particle size as it relates to the minimum film formation temperature of lattices. Journal of Applied Polymer Science 1991, 42, (10), 2845-2849.

29. Royall, C. P.; Thiel, B. L.; Donal, A. M., radiation damage of water in environmental scanning electron microscopy. Journal of Microscopy 2001, 204, (3), 185-195.

30. Sanderson, R. T., Chemical bond and bond energy. New York, 1971; p 222.

31. Vollhardt, K. C.; Schore, N. E., Organic chemistry 4th Ed. New york, 2003; p 121.

32. Cuthbert, S. J.; Buckman, J. O., Charge contrast imaging of fine-scale microstructure and compositional variation in garnet using the environmental scanning electron microscope. Amrican Mineralogist 2005, 90, 701-707.

33. Marechal, E.; Mercier, J. P., Chimie des polymères-Synthèses, réactions et dégradations. 1999; p 448.

34. Hellgren, A. C.; Weissenborn, P.; Holmberg, K., surfactant in waterborne paints. Progress in Organic Coatings 1999, 35, (1-4), 79-87.

35. Backfolk, K.; Andersson, C.; Peltonen, J., Association between a sodium salt of a linear dodecylbenzene sulphonate and a non-ionic fatty alcohol ethoxylate surfactant during film formation of styrene/butadiene latex. Colloids and Surfaces A: Physicochemical and Engineering Aspects 2006, 291, (1-3), 38-44.

36. Jowkar-Deriss, M.; Karlsson, O. J., Morphologies and droplet sizes of alkyd-acrylic hybrids with high solids content. Colloids and Surfaces a-Physicochemical and Engineering Aspects 2004, 245, (1-3), 115-125. 